\title{
The Use of Antiepileptic Drug Levels In Children: A Survey of Canadian Pediatric Neurologists
}

\author{
J.M. Dooley, P.R. Camfield, C.S. Camfield, K.E. Gordon and A.D. Fraser
}

\begin{abstract}
There are 60 pediatric neurologists in Canada. Replies were received from 56 in response to a survey regarding the use and perceived value of antiepileptic drug (AED) levels. AED levels are frequently ordered and influence clinical care. There were, however, discrepancies among pediatric neurologists regarding the upper and lower limits of the "therapeutic ranges" and the clinical application of levels. We suggest that both the value and use of AED levels needs further study.
\end{abstract}

RÉSUMÉ: Enquête sur l'utilisation des niveaux d'anticonvulsivants chez les enfants par les neurologues pédiatriques Canadiens. Il y a 60 neurologues pédiatriques au Canada. Nous avons reçu une réponse à un questionnaire concernant l'utilisation et la valeur imputée aux niveaux sanguins de médicaments anti-épileptiques (MAE) de 56 d'entre eux. Les niveaux de MAE sont souvent demandés et influencent les décisions cliniques. Cependant, il existait des discordances parmi les neurologues pédiatriques concernant la limite supérieure et inférieure de l'écart thérapeutique et l'application clinique de cette information. Nous suggérons que la valeur et l'utilisation des niveaux de MAE devraient faire l'objet d'études plus poussées.

Can. J. Neurol.Sci. 1993; 20:217-221

The value of monitoring antiepileptic drug (AED) concentrations in clinical practice has been debated since their introduction by Buchthal et al. more than 30 years ago.' Some studies have suggested that measuring drug concentrations may enhance seizure control, ${ }^{2}$ while others indicated that their routine use may not improve the treatment of epilepsy. ${ }^{3}$

The goal of drug treatment in epilepsy is to achieve seizure control with minimal toxicity, a balance that occurs at varying serum AED concentrations for each individual. None of the accepted therapeutic ranges will apply to every patient with epilepsy.

Serum levels have been shown to be poorly correlated with seizure control for phenytoin, ${ }^{4}$ carbamazepine, ${ }^{5.6}$ phenobarbital ${ }^{7}$ and ethosuximide, ${ }^{8}$ while others have claimed a relationship between AED levels and control of seizures. ${ }^{9}$ Similarly, toxicity may be unrelated to the AED level. ${ }^{10}$ Important unwanted effects in children, including behavioral problems on phenobarbital therapy" and hepatotoxicity on valproate therapy, ${ }^{12}$ are apparently unrelated to serum levels. In addition other adverse effects may be either idiosyncratic or allergic. It has also been proposed that certain AED metabolites, such as carbamazepine-10, 11-epoxide, may play a role in the production of side effects. ${ }^{13,14}$

There are no available data on how pediatric neurologists or pediatricians use AED levels when caring for children with epilepsy. We studied the use and perceived value of AED levels in clinical practice, as reported by Canadian pediatric neurologists.

\section{METHODS}

All 60 pediatric neurologists in Canada were asked to complete a questionnaire regarding the use of AED monitoring. The questions established the following information: A) Demographic data regarding the type of practice, percentage of time spent in clinical practice and number of patients with epilepsy seen. B) The respondents were requested to report how often, and under what circumstances, they order AED measurements. When "trough" AED levels were measured they were questioned whether the usual AED dose was delayed and if so for how long. They were asked if their clinical decisions were influenced by AED values (including carbamazepine-10, 11 epoxide levels, where available) and what percentage of measurements were used to monitor patient compliance. C) Another series of questions presented 3 case histories which required a response in a multiple choice format. These cases addressed the issue of how AED levels might influence the decision to alter the drug dose, as described below. D) Four further cases required a "Yes" or "No" answer and explored opinions about when an AED level was worth obtaining. E) The remaining

From the Departments of Pediatrics and Toxicology, Dalhousie University and The IWK Children's Hospital, Halifax

Received October 20, 1992. Accepted in final form February 11, 1993

Reprint requests to: Dr. J.M. Dooley, Neurology Division, The IWK Children's Hospital, University Avenue, Halifax, Nova Scotia, Canada B3J $3 G 9$ 
question sought the "accepted therapeutic range" for carbamazepine, phenobarbital, phenytoin, valproate and ethosuximide.

\section{Results}

\section{Demographic Data}

Replies were received from 56 of the 60 pediatric neurologists in Canada (93\%). Of these $47(84 \%)$ were in full time or part time academic practice. Five were in private practice and 4 were described as partially retired. Most (40 or $71.5 \%$ ) spent more than half of their working day in clinical practice and only 3 spent less than $25 \%$ of their time in clinical care. During the previous 4 working weeks, $49(87.5 \%)$ had seen more than 10 patients with epilepsy and of the remaining six, 5 had seen between 6 and 10 patients with seizures and 1 had only seen 1-5 epileptic patients.

\section{Reported Use of AED}

In this section respondents were asked if they measured AED levels always, frequently, seldom or never at each situation. As AED levels could be frequently ordered on more than one occasion the numbers do not add up to $100 \%$.

In general AED levels were frequently ordered. Twenty-six $(46.4 \%)$ reported that they had ordered drug measurements in more than half of their last 20 patients with seizures. A further $11(20 \%)$ reported that they had measured levels in $25-50 \%$ of their patients.

Three questions asked whether measured levels were measured always, frequently, seldom or never at each of the following times: 1. pre-dose (trough), 2. at expected peak and 3. when the patient is seen irrespective of the time of medication dose. Drug concentrations were measured frequently or always: pre-dose by $32(63 \%)$, at the expected peak by $9(18.3 \%)$ and at whatever time the patient was seen in clinic by $31(59.6 \%)$. If trough levels were ordered, $40(71 \%)$ asked their patients to delay their morning AED dose and for $46(82 \%)$ this delay ranged from 30 to 120 minutes.

AED levels were frequently ordered as each office visit by $21(38 \%)$ of respondents. The majority ( 46 or $82 \%$ ) reported that they always or frequently ordered drug measurements after introducing the first AED or if a second AED was added to a patient's treatment regime (43 or $77 \%$ ). Levels were measured by $39(70 \%)$ when a compliant patient had seizures on low dose compared to $53(96 \%)$ if the same patient was on high dose medication. Fifty-three $(96 \%)$ ordered a drug measurement if a patient had possible toxicity and $52(95 \%)$ did so if compliance was in doubt. Levels were routinely assessed once or twice a year by $33(60 \%)$ and more than twice per year by $10(18 \%)$.

Carbamazepine 10-11 epoxide levels were readily available for only 12 physicians and only 9 were frequently influenced by the serum concentration of this metabolite.

A small percentage of the total number of levels ordered were to monitor compliance; $45(80 \%)$ reported that less than $25 \%$ of the levels ordered, were used for this reason. In general therapeutic drug monitoring was perceived as valuable and results always $(2$ or $4 \%$ ) or frequently $(42$ or $75 \%$ ) influenced clinical decisions.

\section{Case Management}

Three case histories explored the impact of serum levels on decisions about treatment. The responses to these case histories were varied. The first case examined the role of levels in a patient with improved, but incomplete, control of complex partial seizures on carbamazepine therapy. The patient was a 9-year-old boy on Tegretol CR, $300 \mathrm{mg}$. BID. He had no apparent sideeffects and his serum CBZ concentration, collected 3 hours following his dose, was $38 \mu \mathrm{mol} / \mathrm{L}(9 \mu \mathrm{g} / \mathrm{ml})$. The "therapeutic range" was presented as 13-40 $\mu \mathrm{mol} / \mathrm{L} .(3-9.4 \mu \mathrm{g} / \mathrm{ml})$. A decison to increase the carbamazepine dose was made by $26(46.4 \%)$, while $3(5.4 \%)$ suggested adding a second AED and $17(30.4 \%)$ elected to measure a trough level. A further $8(14.3 \%)$ opted to change nothing but reexamine the patient in one month and the remaining 2 physicians selected none of the choices given.

The second case explored the issue of good seizure control without side-effects but a low AED serum level. The patient was a 14-year-old girl with generalized tonic-clonic seizures who was unable to take valproate, but was free of both seizures and adverse effects on phenobarbital $45 \mathrm{mg}$. BID. Her phenobarbital level was $40 \mu \mathrm{mol} / \mathrm{L}(9 \mu \mathrm{g} / \mathrm{ml})$ with the therapeutic range given as $60-150 \mu \mathrm{mol} / \mathrm{L}(13-33 \mu \mathrm{g} / \mathrm{ml})$. The majority, $36(64.3 \%)$, decided not to alter treatment or measure the drug in this patient's serum. An increase in the phenobarbital dose was suggested by $11(19.6 \%)$, 1 suggested the addition of a second AED, 4 wished to "change nothing and reexamine the patient in 1 month" and 4 selected "none of the above."

The third case addressed incomplete seizure control with high AED serum levels. The answers were even more varied in this case, an adolescent with occasional atypical absence seizures despite being on valproate, $1500 \mathrm{mg}$. BID. Her trough level was $1050 \mu \mathrm{mol} / \mathrm{L}(152 \mu \mathrm{g} / \mathrm{ml}$ ) (therapeutic range $350-700$ $\mu \mathrm{mol} / \mathrm{L}, 50-100 \mu \mathrm{g} / \mathrm{ml})$. She had no side-effects. Only $9(16.4 \%)$ decided to increase her dose compared to $12(22 \%)$ who elected to do nothing but reassess her in 1 month. A second AED was added by $9(16.4 \%), 4(7.3 \%)$ replaced valproate with another AED and 2 measured a peak serum level. Changing the valproate preparation was suggested by 1 individual. Sixteen $(32 \%)$ felt that none of the options was appropriate, and 3 of these physicians suggested decreasing the valproate dose, despite the persistence of seizures.

\section{Questions Requiring “Yes/No" Answers}

When the pediatric neurologists were asked to state whether they would or would not order drug monitoring in a particular situation, the replies were more consistent. Only $16(28.6 \%)$ ordered a drug measurement in a patient who was free of both seizures and side-effects for 6 months on carbamazepine. If the patient had 2 seizures, during the same interval, $47(83.9 \%)$ measured a level. When a patient had a rash while on carbamazepine only 1 person elected to measure a level. Finally when a patient complained of mid-morning dizziness, during the 8 th week of Dilantin therapy, $52(93 \%)$ thought a level should be checked.

\section{Therapeutic Ranges}

All respondents were asked to list the "therapeutic range" quoted by their laboratory. The ranges for phenytoin were the most consistent. There were 48 responses to this question and 46 gave the upper limit of the range as $80 \mu \mathrm{mol} / \mathrm{L}(20 \mu \mathrm{g} / \mathrm{ml})$ 
while 43 reported the lower limit as $40 \mu \mathrm{mol} / \mathrm{L}(10 \mu \mathrm{g} / \mathrm{ml})$. One response indicated a range of $20-40 \mu \mathrm{mol} / \mathrm{L}(5-10 \mu \mathrm{g} / \mathrm{ml}), 3 \mathrm{sug}-$ gested $20-80 \mu \mathrm{mol} / \mathrm{L}(5-20 \mu \mathrm{g} / \mathrm{ml})$ and another physician reported a therapeutic range of $60-80 \mu \mathrm{mol} / \mathrm{L}(15-20 \mu \mathrm{g} / \mathrm{ml})$. The final suggested range was $40-120 \mu \mathrm{mol} / \mathrm{L}(10-30 \mu \mathrm{g} / \mathrm{ml}$ ) (Figure 1 ).

Valproate ranges were relatively uniform. Of 46 responses 44 (96\%) gave the lower limit of the range as $350+/-50 \mu \mathrm{mol} / \mathrm{L}$ $(50+/-7 \mu \mathrm{g} / \mathrm{ml})$. The remaining 2 replies indicated a lower range of $276 \mu \mathrm{mol} / \mathrm{L}(40 \mu \mathrm{g} / \mathrm{ml})$. An upper end of $700+/-50$ $\mu \mathrm{mol} / \mathrm{L}(100+/-7 \mu \mathrm{g} / \mathrm{ml})$ was accepted by $42(91.3 \%)$. The top of the therapeutic range was reported as $500 \mu \mathrm{mol} / \mathrm{L}(72 \mu \mathrm{g} / \mathrm{ml})$ by 2 and $600(87 \mu \mathrm{g} / \mathrm{ml})$ and $1035 \mu \mathrm{mol} / \mathrm{L}(150 \mu \mathrm{g} / \mathrm{ml})$ each by 1 pediatric neurologist (Figure 1).

For phenobarbital there were 49 replies with $42(86 \%)$ reporting a lower range of $65+/-5 \mu \mathrm{mol} / \mathrm{L}(14.5+/-1 \mu \mathrm{g} / \mathrm{ml})$. The "lower end" ranged from $42(9 \mu \mathrm{g} / \mathrm{ml})$ to $90 \mu \mathrm{mol} / \mathrm{L}(20$ $\mu \mathrm{g} / \mathrm{ml})$. The upper end of the therapeutic range was more varied. A level of $170+/-10 \mu \mathrm{mol} / \mathrm{L}(38+/-2 \mu \mathrm{g} / \mathrm{ml})$ was accepted by $28(57 \%)$ physicians. The upper limit of the accepted therapeutic range varied from $90 \mu \mathrm{mol} / \mathrm{L}(20 \mu \mathrm{g} / \mathrm{ml})$ to $215 \mu \mathrm{gmol} / \mathrm{L} \mathrm{(48}$ $\mu \mathrm{g} / \mathrm{ml}$ ) (Figure 1).

Only $36 \%$ gave an accepted range for ethosuximide. Of these $33(92 \%)$ felt the lower end was $300+/-50 \mu \mathrm{mol} / \mathrm{L}(40+/-6.5$ $\mu \mathrm{g} / \mathrm{ml}$ ) and 32 reported the upper end as $700+/-50 \mu \mathrm{mol} / \mathrm{L}(93$ $+/-6.5 \mu \mathrm{g} / \mathrm{ml}$ ). Again there was a lack of consistency in the reports of both lower end $(200 \mu \mathrm{mol} / \mathrm{L}(26.5 \mu \mathrm{g} / \mathrm{ml})$ to 500 $\mu \mathrm{mol} / \mathrm{L}(66.6 \mu \mathrm{g} / \mathrm{ml}))$ and upper end of the therapeutic range $(400 \mu \mathrm{mol} / \mathrm{L}(53 \mu \mathrm{g} / \mathrm{ml})$ to $1125 \mu \mathrm{mol} / \mathrm{L}(150 \mu \mathrm{g} / \mathrm{ml})$.
There were $50(89 \%)$ replies to the question on the therapeutic range for carbamazepine. There was a remarkable inconsistency in the lower end of the range reported. A lower limit of the therapeutic range below $18 \mu \mathrm{mol} / \mathrm{L}(4.2 \mu \mathrm{g} / \mathrm{ml})$ was used by 26 (52\%) while $17(34 \%)$ used a level of $30 \mu \mathrm{mol} / \mathrm{L}(7 \mu \mathrm{g} / \mathrm{ml})$ or higher as the lower limit. The bottom of the range varied from 13 to $40 \mu \mathrm{mol} / \mathrm{L}(3-9.4 \mu \mathrm{g} / \mathrm{ml})$. The upper limit was also variable, being $>50 \mu \mathrm{mol} / \mathrm{L}(12 \mu \mathrm{g} / \mathrm{ml})$ for $30(60 \%)$ but $<35 \mu \mathrm{mol} / \mathrm{L}(8$ $\mu \mathrm{g} / \mathrm{ml}$ ) for $4(9 \%)$ (Figure 1$)$. In addition, there were 11 reports of a lower limit to the therapeutic range of $>34 \mu \mathrm{mol} / \mathrm{L}$ ( 8 $\mu \mathrm{g} / \mathrm{ml}$ ) while 4 used this as the upper end of their optimal range.

Therefore some pediatric neurologists use a lower limit which is higher than the upper limit of others for phenytoin, ethosuximide and carbamazepine. The greatest variability was seen for carbamazepine.

\section{Discussion}

In this study we ascertained the reported use of AED levels by $93 \%$ of Canadian pediatric neurologists. Almost all of the pediatric neurolgists in Canada are in academic practice, as were $84 \%$ of those responding to the questionnaire. This group is clinically active and is involved in the care and treatment of children with epilepsy. They frequently monitor AED levels and most obtain blood samples after starting therapy, adding a second AED, if compliance is in doubt or if toxicity is suspected. Sixty percent also routinely monitor levels every 6-12 months. This may reflect the severity of epilepsy in patients followed by this group of physicians. At a 6 month follow-up visit only $28.6 \%$

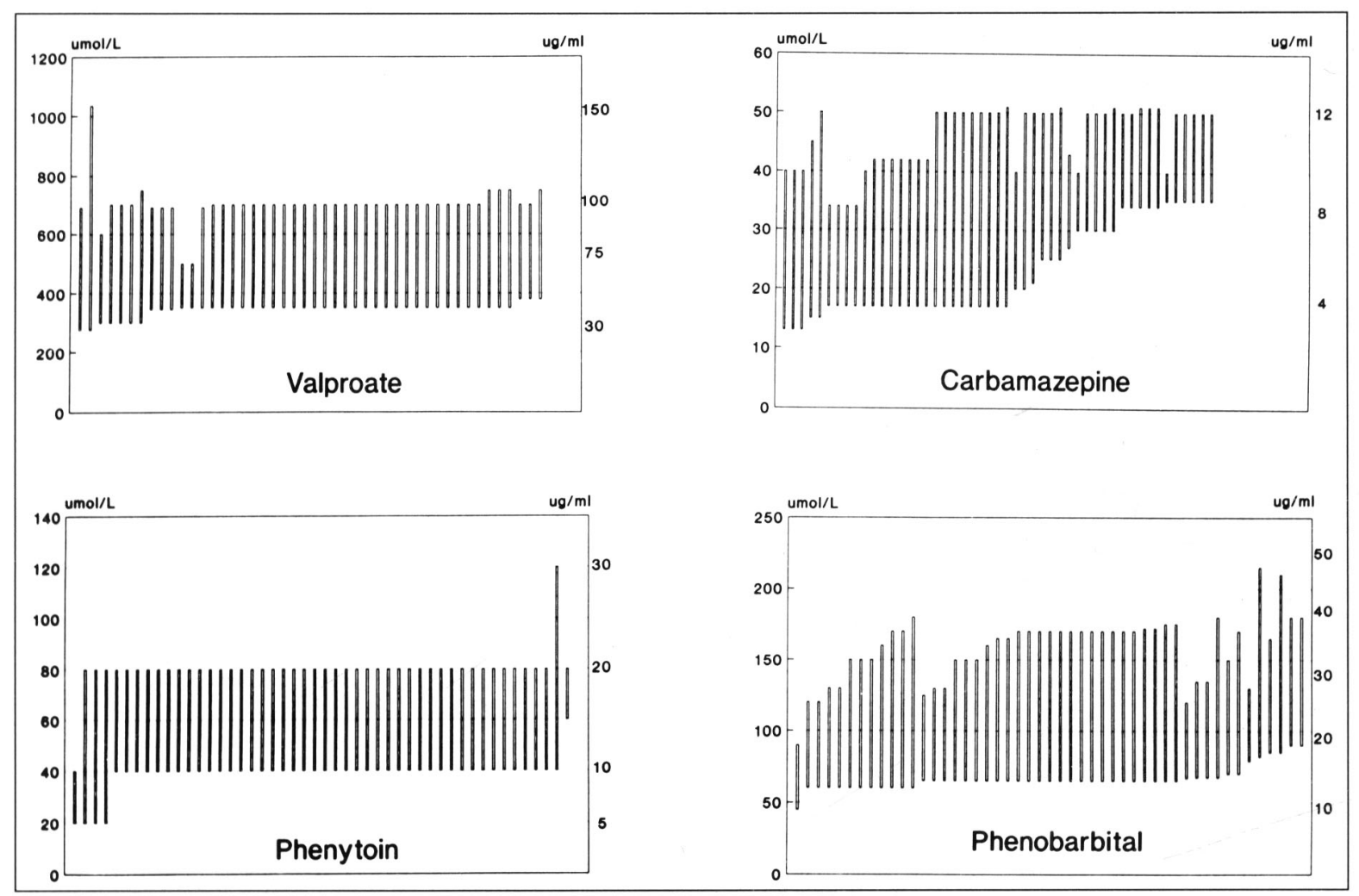

Figure I-Surveyed therapeutic ranges for 4 anticonulsant medications. Each bar indicates the response of I pediatric netrologist. 
elected to order a drug measurement in a clinically well patient compared to $84 \%$ if the patient was having seizures.

Although carbamazepine-10, 11 -epoxide may be important in the production of side-effects, it influenced clinical decisions for only 9 respondents.

A small percentage of the total number of levels requested, were ordered to monitor compliance, although if compliance was in doubt almost all measured a level. It has been shown, however, that a detailed history is more effective in detecting noncompliance than one random or scheduled drug measurement. ${ }^{14}$

When questioned about specific clinical cases the responses were more varied. Slighly less than half increased the carbamazepine dose in a patient without side-effects who was still having seizures despite a level of $38 \mu \mathrm{mol} / \mathrm{L}(9 \mu \mathrm{g} / \mathrm{ml})$. The therapeutic range was given as $13-40 \mu \mathrm{mol} / \mathrm{L}(3-9.4 \mu \mathrm{g} / \mathrm{ml})$, but the accepted therapeutic ranges varied greatly from one physician to the next. An emphasis on the clinical state rather than the serum level was shown by $64 \%$ for a patient who was clinically well but had a low phenobarbital level. This is consistent with the recommendations of Woo et al. ${ }^{3}$

Canadian pediatric neurologists were even less uniform in their approach to a patient with a high serum valproate value. Although a number of studies have found no correlation between toxicity and serum levels for valproate, ${ }^{10.15-17}$ only $16 \%$ elected to increase the dose in a girl who was free of side-effects but still had seizures. Some respondents decided to decrease the dose despite the persistence of seizures.

The absence of an association between hypersensitivity reactions and serum concentrations was uniformly appreciated, with 1 exception.

Although almost $80 \%$ reported that they were clinically influenced by levels, the therapeutic ranges used in different centres varied greatly. The lower limit for carbamazepine varied from $13-40 \mu \mathrm{mol} / \mathrm{L}(3-9.4 \mu \mathrm{g} / \mathrm{ml})$ while the upper limit varied from $34-51 \mu \mathrm{mol} / \mathrm{L}(8-12 \mu \mathrm{g} / \mathrm{ml})$. Thus a patient with a level of $34 \mu \mathrm{mol} / \mathrm{L}(8 \mu \mathrm{g} / \mathrm{ml})$ would be considered to be possibly "toxic" by 4 physicians while 11 would consider him "subtherapeutic". It is not clear if this variance has any influence on the outcome of patients with epilepsy under the care of the different physicians.

The therapeutic ranges for the other AEDs were more uniform but the highest and lowest ranges reported were still disparate (Table 1). For all drugs a patient with a level at either end of the range might be treated very differently in different centres.

The use of AED levels to make decisions about dose changes based on samples obtained at various random times during the day should be discouraged. Numerous variables, such as the influence of food on the rate of drug absorption, make such

Table 1: Reported Therapeutic Ranges

\begin{tabular}{lcc}
\hline \hline \multicolumn{1}{c}{ AED } & Lower Limit & Upper Limit \\
\hline Carbamazepine & $13-40$ & $34-51$ \\
Phenytoin & $20-60$ & $40-120$ \\
Phenobarbital & $42-82$ & $90-215$ \\
Valproate & $276-380$ & $500-1035$ \\
Ethosuximide & $200-500$ & $400-1125$ \\
\hline
\end{tabular}

Range of levels reported as lower and upper limits of therapeutic range for 5 anticonvulsant medications. results very difficult to interpret. Most authorities suggest that when AED efficacy is questioned, the blood samples should be obtained before the morning dose of medication. ${ }^{18-20}$ The therapeutic ranges established for all AEDs are based on trough drug measurements, collected after the patient is at steady state. The use of such trough levels may be more practical for patients who live in an urban setting with easy access to an epilepsy clinic. Almost $60 \%$ reported that they frequently measure the level whenever the patient presents to clinic. This may reflect the reality that many Canadians must travel long distances from their rural homes to an urban academic centre to see their pediatric neurologist.

The interpretation of AED levels may be misleading since trough level collections are impractical for many patients and because there are considerable discrepancies in the "therapeutic ranges" used. In addition, there is great variability in their use, even by a group of academic pediatric neurologists. The value of carbamazepine levels in particular must be questioned based on this survey.

Based on our data it is not possible to formulate specific guidelines for the use or interpretation of AED levels in children with epilepsy.

In conclusion, our study showed that AED levels are frequently ordered and usually influence clinical decisions, despite discrepancies in the accepted therapeutic ranges and the continuing controversy in the literature regarding their validity. This study is descriptive and there may be differences between the responses to our questions and what is actually done in clinical practice. Nonetheless it appears that further studies are needed to establish the legitimacy and value of therapeutic levels for children with epilepsy.

\section{REFERENCES}

1. Buchthal F, Svensmark O, Schiller PJ. Clinical and electroencephalographic correlations with serum levels of diphenylhydantoin. Arch Neurol 1960; 2: 624-630.

2. Wing DS, Duff HJ. The impact of a therapeutic drug monitoring program for phenytoin. Ther Drug Monit 1989; 11:32-37.

3. Woo E, Chan YM, Yu YL, Chan YW, Huang CY. If a well-stabilized epileptic patient has a subtherapeutic antiepileptic drug level, should the dose be increased? A randomized prospective study. Epilepsia 1988; 29: 129-139.

4. Dawson KP, Jamieson A. Value of blood phenytoin estimation in management of childhood epilepsy. Arch Dis Child 1971; 46: 386-388.

5. Shorvon SD, Chadwick D, Galbraith AW, Reynolds EH. One drug for epilepsy. Br Med J 1978; 1: 474-476.

6. Callaghan N, O'Callaghan M, Duggan B, Feely M. Carbamazepine as a single drug in the treatment of epilepsy. J Neurol Neurosurg Psychiatry 1978; 41: 907-912.

7. Buchanan RA, Allen RJ. Diphenylhydantoin (Dilantin) and phenobarbital blood levels in epileptic children. Neurology 1971; 21 : 866-871.

8. Blomquist HK, Zetterlund B. Evaluation of treatment in typical absence seizures. Acta Paediatr Scand 1985; 74: 409-415.

9. Lund L. Anticonvulsant effect of diphenylhydantoin relative to plasma levels. A prospective three-year study in ambulant patients with generalized seizures. Arch Neurol 1974; 31: 289 294.

10. Herranz JL, Arteaga R, Armijo JA. Side effects of sodium valproate in monotherapy controlled by plasma levels: a study in 88 pediatric patients. Epilepsia 1982; 23: 203-214.

11. Herranz JL, Armijo JA, Arteaga R. Clinical side effects of phenobarbital, primidone, phenytoin, carbamazepine and valproate during monotherapy in children. Epilepsia 1988; 29: 794-804. 
12. Scheffner D, Konig S, Rauterberg-Ruland I, Kochen W, Hofmann WJ, et al. Fatal liver failure in 16 children with valproate therapy. Epilesia 1988; 29: 530-542.

13. Patsalos PN, Stephenson TJ, Krishna S, Elyas AA, Lascelles PT, et al. Side-effects induced by carbamazepine-10, 11-epoxide. Lancet $1985 ; 2: 496$.

14. Schoeman JF, Elyas AA, Brett EM, Lascelles PT. Correlation between plasma carbamazepine-10, 11 -epoxide concentration and drug side-effects in children with epilepsy. Dev Med Child Neurol 1984; 26: 756-764.

15. Choonara IA, Rane A. Therapeutic drug monitoring of anticonvulsants: state of the art Clin. Pharmacokinet 1990; 18: 318-328.
16. Gram L, Flachs H, Wurtz-Jorgensen A, Parnas J, Andersen B. Sodium valproate, serum levels and clinical effect in epilepsy: a controlled study. Epilepsia 1979; 20: 303-312.

17. Ruuskanen I, Kilpelainen HO, Riekkinen PJ. Side effects of sodium valproate during long-term treatment in epilepsy. Acta Neurol Scand 1979; 60: 125-128.

18. Porter RJ. In: Major Problems in Neurology, Vol. 12: Epilepsy, 100 Elementary Principles. W.B. Saunders Co. Ltd. 1984: 70.

19. Aicardi J. In: Epilepsy in Childern, New York, Raven Press, 1986: 334.

20. Holmes GL. In: Major Problems in Clinical Pediatrics, Vol. 30: Diagnosis and Management of Seizures in Childhood. W.B. Saunders Co. Lid. 1987: 79. 